\title{
Diagenetic reactivity of the plutonium in marine anoxic sediments (Cumbrian mud patch - eastern Irish Sea)
}

\author{
A. Gouzy ${ }^{1,2}$, D. Boust ${ }^{1}$, O. Connan ${ }^{1}$, G. Billon ${ }^{3}$, L. León Vintró ${ }^{4}$, J. Lucey ${ }^{4}$, \\ L. Bowden ${ }^{4}$, M. Agarande ${ }^{5}$, S. Lesourd ${ }^{6}$, P. Lesueur ${ }^{2}$, A. Klein $^{1,2}$, \\ P.J. Kershaw ${ }^{7}$ and P.I. Mitchell ${ }^{4}$ \\ ${ }^{1}$ Laboratoire de Radioécologie de Cherbourg-Octeville, IRSN, 50130 Cherbourg-Octeville, \\ France \\ ${ }^{2}$ UMR CNRS 6143 Morphodynamique Continentale et Côtière, Université de Caen, \\ 14000 Caen, France \\ ${ }^{3}$ Laboratoire de Chimie Analytique et Marine, FR CNRS 1818 et UMR CNRS 8013, \\ Université de Lille, 59655 Villeneuve d'Ascq Cedex, France \\ ${ }^{4}$ Department of Exprimental Physics, University College Dublin, Belfield, Dublin 4, Ireland \\ ${ }^{5}$ Laboratoire de Mesure de la Radioactivité de l'Environnement, IRSN, 91400 Orsay, France \\ ${ }^{6}$ Université du Littoral Côte d'Opale, UMR 8013 ELICO, 62930 Wimereux, France \\ ${ }^{7}$ The Centre for Environment, Fisheries \& Aquaculture Science (CEFAS), Lowestoft, UK
}

\begin{abstract}
An extensive diagenetic study carried out on a sediment core collected in the Cumbrian mud patch off the Sellafield nuclear reprocessing plant, is presented. Sequential leaching data, using a thoroughly validated protocol specifically designed to prevent any resorption of the released plutonium in the course of the extraction, demonstrate that a significant proportion of the plutonium is loosely bound to sites that readily exchange with seawater, oxidise upon oxygenated water contact (reactive sulphides) or easily dissolve upon changes in $\mathrm{pH}$. Such a result contradicts many previous sequential extraction studies which have reported that little of the plutonium in Irish Sea sediments is in a readily available form. The profile of dissolved plutonium in pore waters indicates an active uptake process at depth, probably linked to sulphide (Acid Volatile Sulphide) precipitation. These reactive sulphides are liable to act as source of plutonium to the overlying water if they are brought close the interface by bioturbation or in contact with oxygenated seawater by burrowing activity.
\end{abstract}

\section{INTRODUCTION}

Since the early 1950s, low-level liquid radioactive wastes have been discharged into the north-eastern Irish Sea from the British Nuclear Fuels pcl reprocessing plant at Sellafield, Cumbria, UK. Annual discharges, including those of transuranium nuclides, peaked in the mid- to late- 1970s due to increased throughputs and reprocessing of residues, and thereafter declined as new treatment facilities were introduced. Overall, an estimated $120 \mathrm{TBq}$ of ${ }^{238} \mathrm{Pu}, 611 \mathrm{TBq}$ of ${ }^{239},{ }^{240} \mathrm{Pu}$ and $22 \mathrm{PBq}$ of ${ }^{241} \mathrm{Pu}$ have been discharged to the Irish Sea during the period 1952-2000 [1]. Most of the so-called conservative radionuclides are advected northwards and leave the Irish Sea via the North Channel [2], with a smaller proportion being dispersed southwards to the English Channel approaches [3]. In contrast, radionuclides having a strong affinity for sediment particles are quickly removed from the water column by scavenging processes [4-6] onto suspended particulate matter, and accumulate in fine-grain deposits. In the eastern Irish Sea, muddy sediments are confined to the Cumbrian Mud Patch, a large offshore mudflat lying parallel to the Cumbrian coast, off Sellafield, which acts as a very efficient sink for particle-reactive radionuclides, such as transuranics. 
These sediments are known to be subject to extensive physical (tide currents and waves) and biological (benthic organisms) reworking. Furthermore, trawling activities are liable to cause the resuspension of considerable amounts of sediments [7]. Together with post depositional evolution yielding the release of particulate-bound plutonium to the interstitial waters, these processes are liable to enhance the remobilisation and relocation of the plutonium back to the water-column, its advection to distant sites, or its transfer in the food chain.

The plutonium remobilisation from bottom sediments in the Eastern Irish Sea has been evidenced and extensively documented [8]. Nevertheless, the forcing parameters by which the plutonium is released to the water column are still poorly understood. This is due to the fact that very scarce data are available on the behaviour of this element during the diagenesis of marine sediments [9]. In addition, the reliability of previous data on the solid partition of plutonium under anoxic conditions has been put in question by recent data using a sequential extraction protocol specifically designed to avoid some of the pitfalls affecting this technique [10-11]. Here we present new data on the post-depositional reactivity of plutonium, based on an integrated study of the diagenetic processes taking place in the Cumbrian mud patch, including plutonium solid partitioning and pore water data.

\section{MATERIALS AND METHODS}

A collaborative expedition (DIAPLU) to the eastern Irish Sea and intertidal areas of the Cumbrian coast took place in July 2002. The objectives of this sampling campaign were to: (i) determine the solid partitioning of plutonium originating from the discharges by the Sellafield reprocessing plant and (ii) investigate the influence of pore-water chemistry and the development of anoxic conditions on the remobilisation of this element from the sediment to the overlying water column. The main challenges faced by the participating laboratories were the recovery of high-quality sediment and pore water samples, and the maintenance of anoxic conditions throughout the analytical processes employed. Sub-tidal sediment cores were retrieved using a FLUCHA box-corer from aboard the French research vessel Côtes de la Manche (INSU/CNRS). Sediment description and pH-Eh profiling were performed onboard immediately after retrieval, and sub-cores were taken for sedimentological and diagenetic studies. Back in the (field) laboratory, sediment core extrusion and sectioning was carried out in an oxygen-free atmosphere under nitrogen, within a glove box specially designed for the purpose. The cores were sectioned at $2 \mathrm{~cm}$ intervals, an outer rind of sediment was removed to eliminate smear contamination, and the sediment placed in pore water squeezing pots. The pots were placed into a pneumatic squeezing rig, where pore water from each section was extruded and collected in $50 \mathrm{ml}$ disposable plastic syringes. The pore water was then transferred to a separate nitrogen-filled glove box, where it was filtered $\left(0.45 \mu \mathrm{m}\right.$, PURADISC filter) in an inert $\left(\mathrm{N}_{2}\right)$ atmosphere and subdivided into appropriate aliquots in preparation for the different types of analyses. The squeezing pots were disassembled and the sediment immediately frozen inside heavy-duty plastic bags purged with nitrogen, for storage until further analysis by sequential extraction.

A number of parameters were determined on pore water samples (major and trace elements, sulphides, sulphates and dissolved organic carbon) as well as on sediments (some major and trace elements, particulate organic carbon, carbonate content, grain size distribution, gamma-emitting radionuclides). Special attention was paid to both the determination of acid-volatile sulphides (AVS) and chromium reducible sulphides (CRS) [12], and to the solid partitioning of plutonium. A thoroughly validated sequential extraction procedure [13] was applied to the squeezed sediment sections. The protocol employed considers five fractions, namely exchangeable/readily oxidisable (including reactive sulphide - AVS), acido-soluble (including carbonates), reducible, oxidisable (organics and CRS sulphides), and residual fractions (hereafter referred to as R0, R1, R2, R3 and R4, respectively). Plutonium isotopes $\left({ }^{239} \mathrm{Pu},{ }^{240} \mathrm{Pu},{ }^{241} \mathrm{Pu}\right.$ and ${ }^{242} \mathrm{Pu}$ ) were measured in each fraction by ICP-MS, using ${ }^{244} \mathrm{Pu}$ as yield tracer [14]. Owing to the low concentrations expected and the small pore water volumes 
available, the concentrations of dissolved plutonium in interstitial waters were determined by accelerator mass spectrometry (AMS) using the 14UD Pelletron accelerator at the Department of Nuclear Physics, the Australian National University, Canberra, Australia [15]. We report here the data obtained on a subtidal core retrieved from the muddy sediments just off the Sellafield discharge point

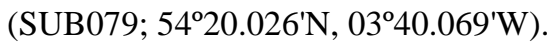

\section{RESULTS AND DISCUSSION}

\subsection{Diagenetic parameters}

No dissolved oxygen was measured in the pore water below the top $5 \mathrm{~mm}$. The constant sulphate $\left(36 \pm 3 \mathrm{mmol} . \mathrm{L}^{-1}\right)$ and alkalinity $\left(3.4 \pm 0.1 \mathrm{~mol} . \mathrm{L}^{-1}\right)$ profiles suggest that if any sulphate reduction is taking place at this site, the sulphate pool is actively being renewed by the overlying water, and is not acting as a limiting factor for the reduction reaction. Nevertheless, evidence that the sediments undergo some suboxic diagenesis is provided by the presence of subsurface peak concentrations of dissolved Mn (II) and Fe (II) in agreement with the thermodynamic predictions, respectively at depths of 1 and $5 \mathrm{~cm}$, and the negative Eh values $\left(-200 \mathrm{mV}\right.$ vs Ag/AgCl, [KCl=3 mol. $\left.\left.\mathrm{L}^{-1}\right]\right)$ measured at depths of $25 \mathrm{~cm}$ down the core (Fig. 1). The pore water Fe concentrations remain roughly constant below the reduction peak $\left(6.5 \pm 0.7 \mathrm{mg} . \mathrm{L}^{-1}\right)$, which indicates that dissolved sulphide production is either not very active, that it occurs in anoxic "micro-niches", or that the sulphides are actively recycled by re-oxidation processes. In addition, peak values of both AVS and particulate organic carbon were found at $13 \mathrm{~cm}$ depth, suggesting that AVS could be produced by the anaerobic decay of autochthonous organisms [16].

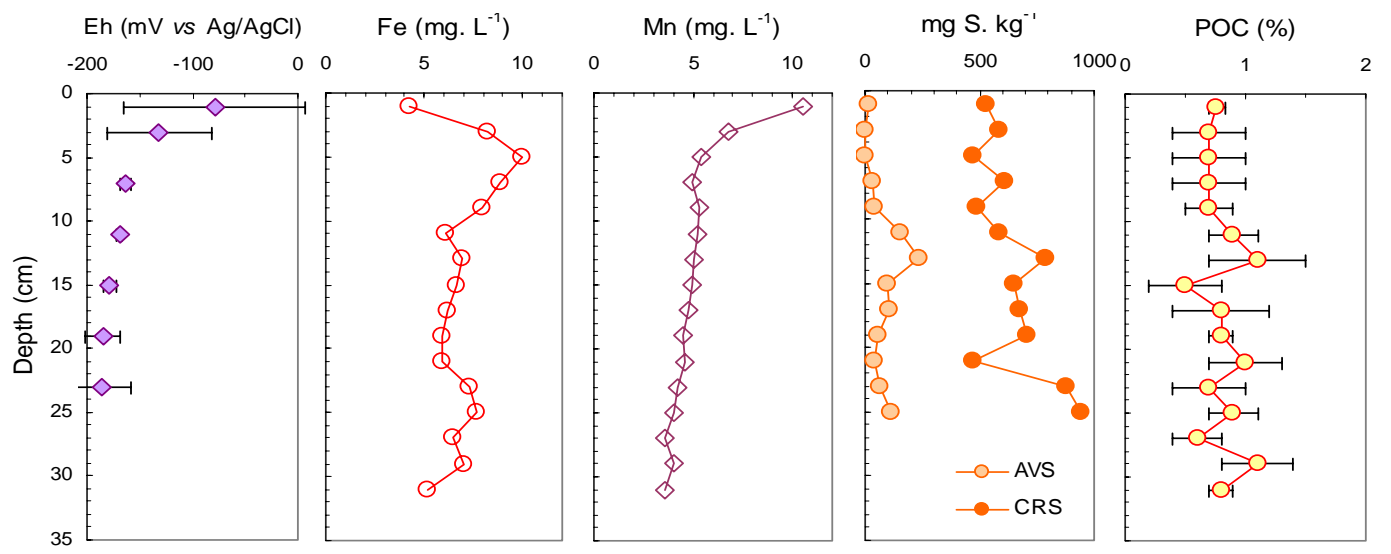

Figure 1. Eh, dissolved Fe and Mn profiles in pore waters, acid volatile (AVS), chromium reducible (CRS) sulphides and particulate organic carbon in core SUB079.

\subsection{Geochemical characterisation of the solid phase}

Grain size analysis indicated that the sediment was predominantly composed of silt (100\% less than $63 \mu \mathrm{m})$. The grain-size distribution displays a bimodal pattern with peak abundances at 8 and $50 \mu \mathrm{m}$, with no significant down-core trend. The non-reactive sediment parameters, such as carbonate content or ${ }^{40} \mathrm{~K}$ concentrations, are essentially constant along the core, at $8.0 \pm 0.4 \%$ and $580 \pm 18 \mathrm{~Bq} \cdot \mathrm{kg}^{-1}$, respectively. By contrast, the ${ }^{137} \mathrm{Cs},{ }^{241} \mathrm{Am}$ and ${ }^{239},{ }^{240} \mathrm{Pu}$ profiles showed a very slight gradient of increasing concentrations with depth, suggesting extensive down-core mixing (Fig. 2). The ${ }^{241} \mathrm{Am} /{ }^{239,}{ }^{240} \mathrm{Pu}$ activity ratios ranged between 1 and 2, compared to 1.5 for the integrated discharge from Sellafield, 
when ingrowth from ${ }^{241} \mathrm{Pu}$ is taken into account. Total concentrations and elemental solid partition between acid-soluble fraction $(1 \mathrm{M} \mathrm{HCl})$ and residual fraction showed that most of the Ca and $\mathrm{Sr}$ was in an acido-soluble form. This is not surprising, as these two elements are known to be associated with the carbonate fraction. In the case of $\mathrm{Mg}$, the acido-soluble component was smaller (69\%), with the remainder most likely bound to the clay minerals, as is most (92\%) of the Al. Significant amounts of Mn (71\%) and, to a lesser extent, Fe (26\%) were in an acido-soluble forms. Both elements are known to be associated with carbonate and sulphide phases in anoxic sediments.
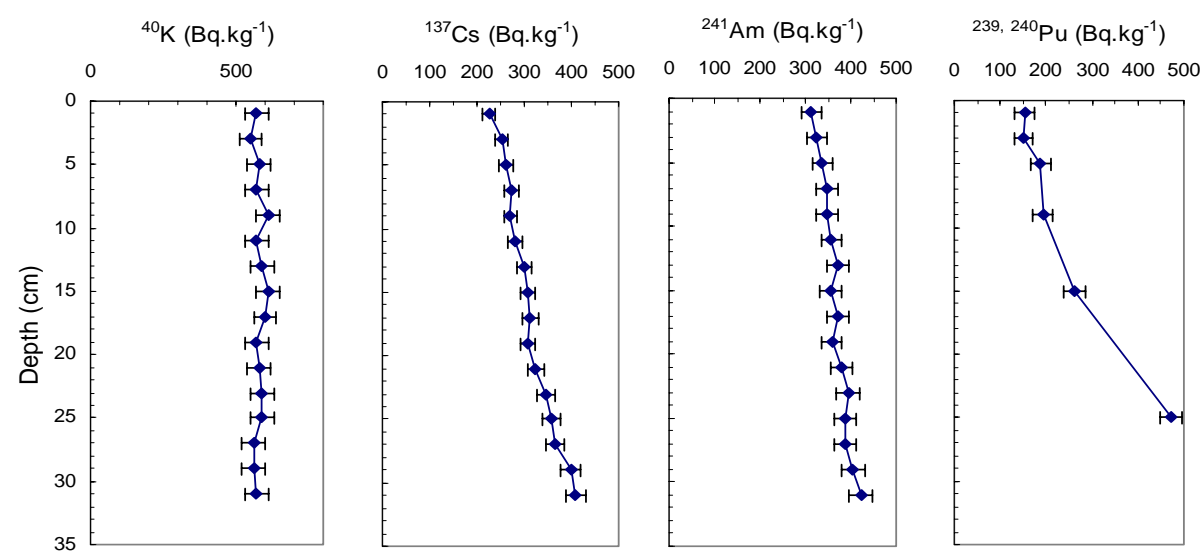

Figure $2 .{ }^{40} \mathrm{~K},{ }^{137} \mathrm{Cs},{ }^{241} \mathrm{Am}$ and ${ }^{239,}{ }^{240} \mathrm{Pu}$ profiles in the core SUB079.

\subsection{Solid partition of the plutonium}

The bulk concentrations of plutonium isotopes $\left({ }^{239} \mathrm{Pu},{ }^{240} \mathrm{Pu},{ }^{241} \mathrm{Pu}\right.$ and $\left.{ }^{242} \mathrm{Pu}\right)$ are given in Table 1 . The average solid partitioning of these isotopes among the fractions defined above (Tab. 2) is very similar to that reported previously on a core collected in the Esk estuary [13]. In both cases, plutonium is mainly associated with the R0 exchangeable/readily oxidisable and R1 acido-soluble fractions. Even if only $10 \%$ of the total plutonium was actually bound to readily oxidisable sulphides, very high and localised concentrations could be reached in these phases (up to 20,000-500,000 Bq of ${ }^{239} \mathrm{Pu}$ per kg of AVS assumed to have a mean composition of FeS) potentially focusing its impact on biota, especially microorganisms. This observation was not expected from previous investigations [17], which took less care of preservation of the anoxic character of the sediment and of resorption of plutonium during the extraction. Since no significant differences were observed in the solid partitioning between the different plutonium isotopes measured, the down core evolution of the plutonium solid partition is examined for the ${ }^{239} \mathrm{Pu}$ only (Fig. 3).

Table 1. Bulk concentrations of plutonium isotopes in the sediments of the core SUB079; Bq. $\mathrm{kg}^{-1}( \pm 2 \sigma)$ at the date of sampling.

\begin{tabular}{ccccc}
\hline Depth $(\mathrm{cm})$ & ${ }^{239} \mathrm{Pu}$ & ${ }^{240} \mathrm{Pu}$ & ${ }^{241} \mathrm{Pu}$ & ${ }^{242} \mathrm{Pu}$ \\
\hline 1 & $88 \pm 8$ & $65 \pm 6$ & $1383 \pm 120$ & $0.040 \pm 0.004$ \\
3 & $86 \pm 7$ & $64 \pm 5$ & $1350 \pm 114$ & $0.040 \pm 0.003$ \\
5 & $109 \pm 21$ & $79 \pm 15$ & $1709 \pm 331$ & $0.055 \pm 0.011$ \\
9 & $111 \pm 11$ & $82 \pm 8$ & $1706 \pm 167$ & $0.052 \pm 0.005$ \\
15 & $150 \pm 13$ & $112 \pm 10$ & $2380 \pm 180$ & $0.071 \pm 0.006$ \\
25 & $274 \pm 16$ & $198 \pm 11$ & $3916 \pm 226$ & $0.125 \pm 0.007$ \\
\hline
\end{tabular}


Table 2. Average solid partition of plutonium isotope activities in the sediments of core SUB079 (mean values of 6 samples; $\pm 1 \sigma$ ). For comparison, the average values for a sediment core from the Esk estuary [13] are also given.

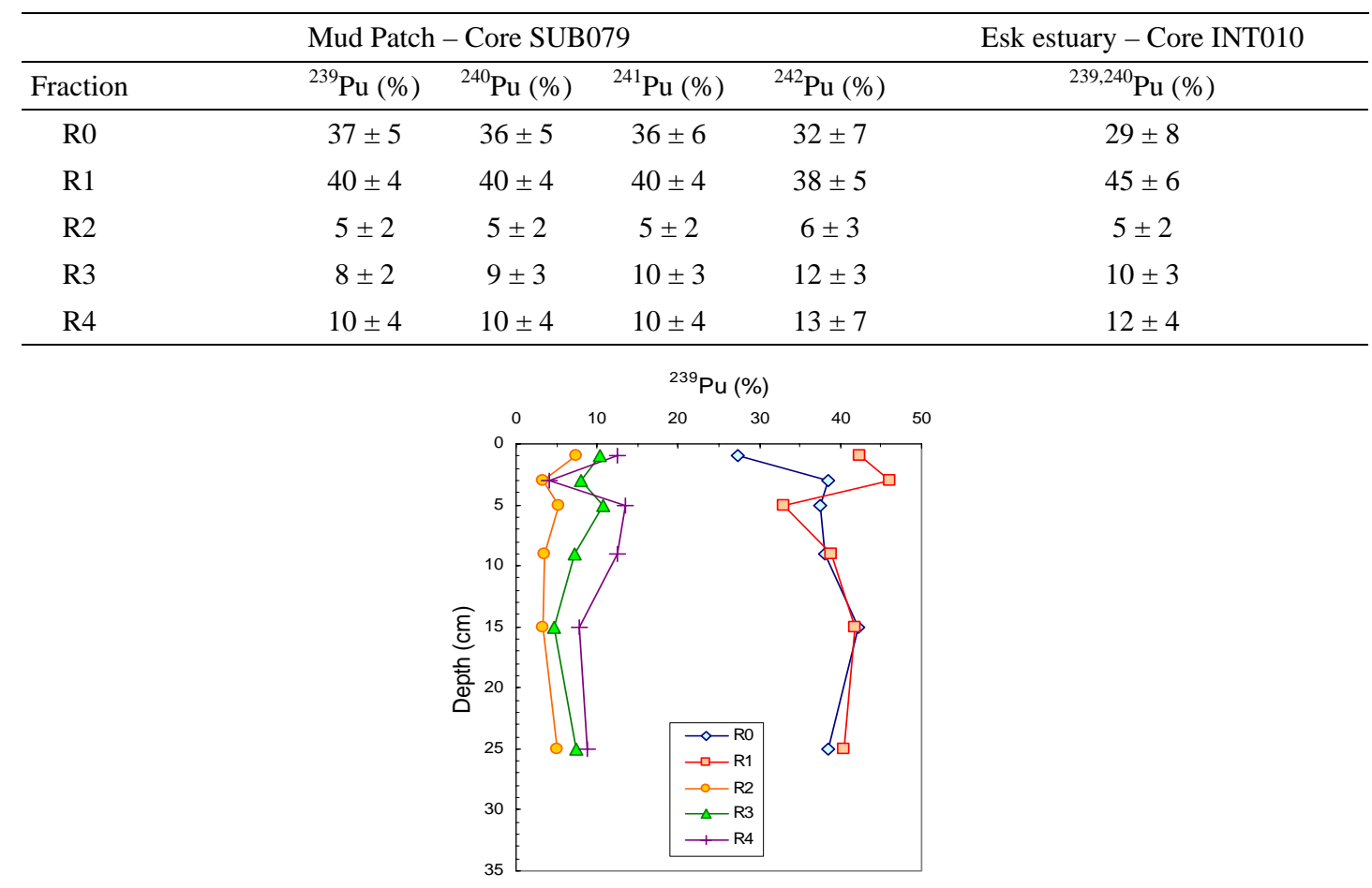

Figure 3. The down core evolution of the ${ }^{239} \mathrm{Pu}$ solid partitioning in the core SUB079; specific activity expressed as percent of the total ${ }^{239} \mathrm{Pu}$.

The down core evolution of the ${ }^{239} \mathrm{Pu}$ solid partition is quite homogenous and does not depend on the total concentration of the element. A slight alteration of the solid partition is observed at $3 \mathrm{~cm}$ depth, whose significance will have to be confirmed by further analyses (Fig. 3). While the plutonium abundance in the R0 fraction ranges between 37 and $42 \%$ at depth, it decreases to $27 \%$ in the topmost sample $(0-2 \mathrm{~cm})$. As this pattern has been observed in some other cores collected nearby, it deserves some further comment, as it represents a release of at least $10 \%$ of the total ${ }^{239} \mathrm{Pu}$ from the exchangeable/readily oxidisable fraction: this process is probably favoured by bioturbation and bioirrigation processes. The water content can reach $48 \%$ close to the sediment-seawater interface, which displays an unstructured flaky texture. Consequently, $\sim 8 \mathrm{~Bq}$ of ${ }^{239} \mathrm{Pu}$ is released from $1 \mathrm{~kg}$ of dry sediment, or $4 \mathrm{~Bq}$ into $0.5 \mathrm{~L}$ of pore water. This is much higher than the ${ }^{239} \mathrm{Pu}$ concentrations measured in the pore waters (see Section 3.4). It is, thus, likely that the plutonium release is followed by its partial resorption onto other sediment phases. Indeed, at this stage, there should be scope for complexation of the released dissolved ${ }^{239} \mathrm{Pu}$ (as $\mathrm{Pu}(\mathrm{IV})$ ) by freshly deposited and actively decaying organic matter (dissolved organic carbon reaches $22 \mathrm{mg} . \mathrm{L}^{-1}$ at $1 \mathrm{~cm}$ depth, compared to an average of 10 in the rest of the core) which could efficiently maintain some of the plutonium in the soluble phase and, consequently, promote its diffusion or advection by bioirrigation to the sediment seawater interface.

\subsection{Plutonium in pore waters}

The vertical profile of dissolved ${ }^{239} \mathrm{Pu}$ is given on Figure 4, with a $2 \mathrm{~cm}$ vertical resolution. The values decrease from $0.52 \mathrm{mBq} . \mathrm{L}^{-1}$ in the surface to $\mathrm{ca} 0.10 \mathrm{mBq} \cdot \mathrm{L}^{-1}$ at $13 \mathrm{~cm}$ depth. The highest concentration, $0.86 \mathrm{mBq} . \mathrm{L}^{-1}$, occurs at $15 \mathrm{~cm}$ depth. This yields $\mathrm{K}_{\mathrm{d}}$ values of 1.7 to $4.3 \times 10^{5} \mathrm{~L}_{\mathrm{kg}} \mathrm{kg}^{-1}$, 
which are typical for these waters [9]. The observed decrease in dissolved ${ }^{239} \mathrm{Pu}$ concentrations suggests an uptake by a solid phase, which is more abundant or more actively formed at depth. As the plutonium has been demonstrated to be partly associated with acid volatile sulphides, the precipitation of reactive iron sulphides is likely to be an efficient uptake process. As shown in Figure $4 \mathrm{~b}$ (where ${ }^{239} \mathrm{Pu}$ and AVS concentrations have been corrected for porosity and are expressed per $\mathrm{dm}^{3}$ of bulk sediment), dissolved ${ }^{239} \mathrm{Pu}$ decreases from 0.32 to $0.05 \mathrm{mBq} . \mathrm{dm}^{-3}$ as AVS content increases up to $147 \mathrm{mgS} . \mathrm{dm}^{-3}$. Further increase of AVS $\left(255 \mathrm{mgS} . \mathrm{dm}^{-3}\right.$ at $\left.13 \mathrm{~cm}\right)$ does not induce further decrease in the dissolved plutonium.

If the AVS are an active sink for plutonium, they can also act as an active source of plutonium to the overlying water, as they are highly sensitive to oxidizing processes (e.g. bioturbation promoting oxidation of AVS by Fe and Mn oxides, bioirrigation promoting oxidation by circulation of oxic seawater, etc.). Indeed, it has been shown that $90 \%$ of the AVS pool can be dissolved after a 1 hour mixing of anoxic sediments in seawater [18]. These processes can occur close to the sediment seawater interface or deeper in the sediment column. In fact, an opened burrow observed in the $15 \mathrm{~cm}$ sample (7 $\mathrm{cm}$ long and $1 \mathrm{~cm}$ diameter) is likely to be responsible of the release of plutonium at this depth. This hypothesis is further supported by the significant decrease of AVS concentration at this depth down to 116 mgS. $\mathrm{dm}^{-3}$.
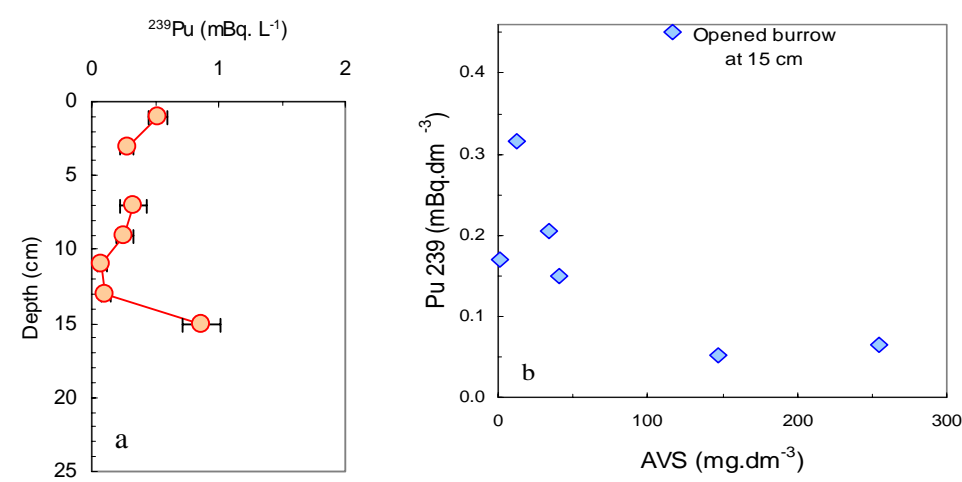

Figure 4. (a) The dissolved ${ }^{239} \mathrm{Pu}$ profile in pore waters of core SUB079; (b) Plot of dissolved ${ }^{239} \mathrm{Pu}$ concentrations versus AVS contents, both corrected for porosity and expressed per $\mathrm{dm}^{3}$ of bulk sediment.

\section{SUMMARY}

This work has shown that plutonium bound to sediment in the Cumbrian mud patch is potentially more bioavailable than hitherto believed. Sequential extraction analyses have shown that a large proportion of the plutonium in Irish Sea sediments is loosely bound to sites that readily exchange with seawater, readily oxidise upon oxygenated water contact or easily dissolve upon changes in $\mathrm{pH}$. Moreover, the data clearly indicate that diagenetic reactions taking place during the development of anoxic conditions influence the partitioning of plutonium in the solid phase. Further experimental evidence of these processes is brought by [19].

Although the results of this work contradict many previous sequential extraction studies, which have reported that little of the plutonium in Irish Sea sediments is in a readily available form, with most publications identifying primary associations with oxide and organic sediment phases, some, at least, of the disparity is almost certainly attributable to failure to take account of the resorption of plutonium in the course of sequential extraction. In addition, many researchers have not taken the necessary precautions to preserve the anoxic integrity of the sediment during sampling, storing and extraction, an omission that undoubtedly leads to unwanted, non-quantifiable phase changes in the course of analysis. 
The plutonium release from bottom sediments partly depends on the recycling of reactive sulphides and is therefore favoured by bioirrigation, bioturbation, and natural and man-induced physical mixing. The comparative study of different cores collected during the DIAPLU will help to further elucidate these processes. The inferred reactivity of plutonium during sediment resuspension will have to be reconsidered as well.

\section{Acknowledgments}

The authors are grateful to the crew of the R.V. "Côtes de la Manche" (CNRS/INSU, France) for their helpful support during the DIAPLU expedition, to the CEFAS team for invaluable assistance at their Whitehaven laboratory and to the LRC-IRSN team for technical assistance, efficiency and analytical expertise. This study was partly funded by the European Commission under its Fifth Framework Programme (REMOTRANS Project, Contract No. FIGE-CT-2000-00085).

\section{References}

[1] León Vintró L. Smith K.J., Lucey J.A. and Mitchell P.I., The environmental impact of the Sellafield discharges, In: Scope-Radsite Workshop, Brussels, 4-6 December 2000, 27pp.

[2] McKay W. A., and Pattenden N. J., J. Environ. Radioactivity, 18 (1993) 99-132.

[3] Garreau P. and Bailly du Bois P., Transportation of radionuclides in the Celtic Sea : a possible mechanism. RADOC Symposium "Inventories, behaviour and processes" Cherbourg-Octeville (France), 7-11 October, 1996, P. Germain, J.C. Guary, P. Guéguéniat and H. Métivier (Radioprotection - colloques, 1997), Vol. 32, C2, 381-385.

[4] Hetherington J.A., Jefferies D.F. and Lovett M.B., Impacts of nuclear releases into the aquatic environment, (IAEA-SM-198, Otaniemi, Finland, IAEA Vienna, 1975) pp 193-212.

[5] Boust D., Mitchell P. I., Garcia K., Condren O., León Vintró L. and Leclerc G. Radiochim. Acta, 74 (1996) 203-210.

[6] Mitchell P. I., Condren O. M., León Vintró L. and McMahon C. A., J. Environ. Radioactivity, 44 (1999) 223-251.

[7] Kershaw P.J., Denoon D.C. and Woddhead D.S., J. Environ. Radioactivity, 44 (1999) 121-221.

[8] Hunt G. J. and Kershaw P. J., Journal of Radiological Protection, 10 (1990) 147-151.

[9] Malcolm S.J., Kershaw P. J., Lovett M.B. and Harvey B.R., Geochim. Cosmochim. Acta, 54 (1989) 29-35.

[10] Walter F., Rapport LERFA-IRSN, Cherbourg-Octeville (2000) 64pp.

[11] Lucey J.A., Solid speciation of the plutonium in the Irish Sea by sequential extraction analysis, PhD University College Dublin (2003) 169pp.

[12] Thode-Andersen S. and Jorgensen B.B., Limnol. Oceanogr., 34 (1989) 793-80.

[13] Lucey J. A., Gouzy A., Boust D., León Vintró L., Bowden L., Finegan P. P., Kershaw P. J. and Mitchell P. I., Applied Radiation and Isotopes, 60 (2004) 379-385.

[14] Agarande M., Benzoubir S., Neiva-Marques A. M., and Bouisset P., J. Environ. Radioactivity, 72 (2004) 169-176.

[15] Fifield L. K., Cresswell R. G., di Tada M. L., Ophel T. R., Day J. P., Clacher A. P., King S. J. and Priest N., Nucl. Instrum. Methods Phys. Res., B117 (1996) 295-303.

[16] Allen R.E., Chem. Geol., 182 (2002) 461-472.

[17] McDonald P., Vives i Battle J., Bouscher A., Whittalli A. and Chambers N., The Science of the Total Environment, 267 (2001), 109-123.

[18] Boust D., Hébert D. et Rozet M., Rapport DPRE/SERNAT/99-13 (1999).

[19] Gouzy A., Boust D. and Klein A., this volume (2004). 